\title{
ENCAPSULAÇÃO DE ÁCIDO RETINÓICO EM MICROEMULSÕES GELIFICADAS
}

\author{
S.G.M.MARTINS* ${ }^{1}$, G.R.LEONARDI ${ }^{2}$, F.A.PERRECHIL ${ }^{1}$ \\ ${ }^{1}$ Universidade Federal de São Paulo, Instituto de Ciências Ambientais, Química e \\ Farmacêuticas \\ ${ }^{2}$ Universidade Estadual de Campinas, Faculdade de Ciências Farmacêuticas \\ * E-mail para contato: sgarzon.mm@gmail.com
}

\begin{abstract}
RESUMO - O ácido retinóico vem sendo amplamente utilizado no tratamento anti-idade, em processos acneicos e de outras lesões cutâneas. No entanto, este retinóide é instável e, quando aplicado diretamente na pele, pode causar rubor e irritação. A fim de resolver esse problema, a encapsulação apresenta-se como um método propício, uma vez que é capaz de proteger o ácido retinóico de ações externas como a luz e o oxigênio, permitir a liberação controlada evitando efeitos adversos, além de promover uma estabilidade prolongada do composto. Assim, o objetivo deste trabalho foi desenvolver microcápsulas a partir da gelificação iônica de microemulsões contendo gelana ou $\kappa$-carragena para a encapsulação de ácido retinóico. As microcápsulas foram avaliadas em relação à microscopia, eficiência de encapsulação e estabilidade do ácido retinóico. Os resultados mostraram que a técnica utilizada promoveu a formação de microcápsulas contendo o óleo encapsulado, porém a eficiência de encapsulação do ácido retinóico foi muito baixa (inferior a 4\%) e o ácido retinóico encapsulado foi totalmente degradado após 4 dias de armazenamento. A partir dos resultados pode-se concluir que a metodologia empregada não foi adequada para a encapsulação e proteção deste tipo de composto.
\end{abstract}

\section{INTRODUÇÃO}

A microencapsulação é uma técnica que vem sendo usada há décadas, estando presente hoje em diversas áreas como a área farmacêutica, cosmética, alimentícia, dentre outras. Dentre as diferentes técnicas empregadas para encapsulação está a gelificação iônica, que é a formação de partículas gelificadas em escala micrométrica. Os compostos principalmente utilizados para o preparo dos microgéis são os biopolímeros, devido à sua biocompatibilidade, percepção como materiais naturais e desenvolvimento de estruturas com textura de sólido deformável (Burey et al., 2008).

As microcápsulas têm como finalidade proteger o recheio de agentes externos como a luz e oxigênio, promovendo uma estabilidade prolongada no período de armazenagem e aplicação, além de permitir a liberação controlada e direcionada do ativo no local de interesse (Jenning e Gohla, 2001). Com isso, é possível aumentar a estabilidade de substâncias que podem se degradar facilmente em contato com o ambiente, ou que causariam efeitos colaterais quando aplicados diretamente, como o ácido retinóico (McClements, 2015; Lara, 2008). 
O ácido retinóico é um metabólito ativo do retinol (vitamina A) amplamente utilizado no tratamento de problemas relacionados à pele quando aplicado topicamente, como acne (Lara, 2008), envelhecimento (Tancrède-Bohin et al., 2015) e no tratamento de outras patologias cutâneas, como psoríase e tumores (Trapasso et al., 2009). Porém, este composto apresenta grande instabilidade, sendo facilmente oxidado, além de ocasionar efeitos adversos quando aplicado diretamente na pele, como irritação e rubor (Silva et al., 2015). Com isso, torna-se altamente favorável o uso da técnica de microencapsulação.

Como o ácido retinóico é um composto hidrofóbico, ele deve ser incorporado em uma fase oleosa em uma etapa anterior à produção das microcápsulas. Essa incorporação pode ser realizada em microemulsões óleo em água $(\mathrm{O} / \mathrm{A})$, devido à presença de óleo na fase dispersa, de forma que o composto de interesse permaneça disperso na fase apolar e protegido por uma camada de surfactante. A encapsulação do ácido retinóico já foi estudada por alguns autores, especialmente em partículas lipídicas sólidas (Lin et al., 2013; Silva et al., 2015) e microemulsões (Trotta et al., 2003; Hwang et al., 2004). No entanto, não foram encontrados trabalhos que avaliassem a encapsulação de ácido retinóico em microemulsões gelificadas, sendo esse um sistema promissor para propiciar uma liberação controlada e prolongar a estabilidade do composto ativo.

Assim, este trabalho teve como objetivo a encapsulação do ácido retinóico a partir da produção de microgéis pela gelificação iônica de microemulsões contendo biopolímeros gelificantes (goma gelana e $\kappa$-carragena) e avaliação dos microgéis produzidos a partir de análises de microscopia ótica, eficiência de encapsulação e estabilidade do ácido retinóico encapsulado.

\section{MATERIAIS E MÉTODOS}

\subsection{Materiais}

Para o preparo das microemulsões foram utilizados ácido retinóico (Fagron, Holanda), óleo de pequi (Mundo dos Óleos, Brasil), surfactante não-iônico Tween 80 (Synth, Brasil) e água deionizada. Como agente gelificante foram utilizados $\kappa$-carragena e goma gelana adquiridas da CP Kelco (EUA) e para a gelificação destes biopolímeros foram utilizados cloreto de potássio $(\mathrm{KCl})$ e de cálcio $\left(\mathrm{CaCl}_{2}\right)$, respectivamente. Os demais reagentes utilizados foram de grau analítico.

\subsection{Preparo de microemulsões}

Inicialmente o ácido retinóico foi adicionado ao óleo de pequi na concentração de $1 \%$ $(\mathrm{m} / \mathrm{v})$. Em seguida, as microemulsões foram preparadas pelo método de emulsificação espontânea à temperatura ambiente. Para isso, uma mistura de surfactante e óleo contendo o ácido retinóico foi preparada sob agitação magnética. Posteriormente, a água foi progressivamente adicionada a esta mistura, sob agitação constante (Cui et al., 2009). A microemulsão preparada apresentou composição final de $70 \%$ de água, $24 \%$ de Tween $80,6 \%$ de óleo e $0,06 \%$ de ácido retinóico.

\subsection{Microemulsões contendo biopolímeros}


Os biopolímeros ( $\kappa$-carragena e gelana) foram adicionados diretamente na forma de pó à microemulsão óleo em água $(\mathrm{O} / \mathrm{A})$ previamente preparada através da metodologia descrita na seção 2.2. As microemulsões foram mantidas sob agitação magnética até completa dissolução dos biopolímeros. A concentração de biopolímeros utilizada de foi $1 \% \mathrm{~m} / \mathrm{v}$.

\subsection{Preparo dos microgéis}

Para o preparo dos microgéis, as microemulsões contendo os polissacarídeos foram extrusadas através de um bico atomizador em solução salina $\left(\mathrm{KCl}\right.$ para a $\kappa$-carragena e $\mathrm{CaCl}_{2}$ para a gelana) sob agitação magnética. O diâmetro de saída do bico atomizador foi fixado em $0,5 \mathrm{~mm}$. As partículas gelificadas foram mantidas em solução salina por 30 minutos e então filtradas e estocadas para futuras análises.

\subsection{Microscopia ótica}

A microestrutura dos microgéis foi avaliada em um microscópio ótico Primo Star (Carl Zeiss, Alemanha), com lentes objetivas de 10x e 40x. Para isso, os microgéis foram colocados em lâminas e cuidadosamente cobertos com lamínulas de vidro. No mínimo 5 imagens foram obtidas para cada amostra.

\subsection{Avaliação da eficiência de encapsulação}

A quantidade de ácido retinóico microencapsulado foi avaliada baseando-se na razão da quantidade de ácido retinóico presente nas microcápsulas biopoliméricas e a quantidade total de ácido retinóico empregada no preparo do sistema microemulsionado. O resultado foi expresso em porcentagem. Para a extração do ácido retinóico das matrizes biopoliméricas, 0,5 $\mathrm{g}$ das microcápsulas foram adicionadas de $5 \mathrm{~mL}$ de solvente extrator (metanol) com agitação por 20 minutos e, em seguida, colocadas em banho de ultrassom por 10 minutos e centrifugadas a $3000 \mathrm{rpm}$ por 15 minutos. O ácido retinóico liberado foi quantificado em espectrofotômetro Evolution 60-S (Thermo Scientific, EUA) em comprimento de onda de 350 nm, utilizando-se uma curva padrão.

\subsection{Avaliação da estabilidade do ácido retinóico}

Para avaliar a estabilidade do ácido retinóico encapsulado, repetiu-se após 4 dias a análise de quantificação do ácido retinóico presente no óleo livre, nas microemulsões e microcápsulas, conforme metodologia descrita no item 2.6. Os dados obtidos foram comparados com os do primeiro dia de preparo do sistema para a avaliação da perda por degradação pelos efeitos da luz ou contato com o ambiente.

\section{RESULTADOS}

As Figuras 1 e 2 apresentam as imagens de microscopia ótica das microcápsulas de gelana e $\kappa$-carragena, respectivamente, preparadas por gelificação iônica das microemulsões contendo ácido retinóico. Observando-se as Figuras 1B e 2B foi possível comprovar a formação das microcápsulas para ambos os materiais de parede utilizados. A partir dessas imagens foi possível observar que as microcápsulas contendo gelana como material de parede apresentaram maior uniformidade, apresentando microcápsulas mais arredondadas, enquanto 
que as microcápsulas contendo $\kappa$-carragena apresentaram assimetria, com formas mais alongadas, achatadas e maiores. Além disso, quando um maior aumento foi utilizado (Figuras 1A e 2A), pode-se verificar que o óleo de pequi foi encapsulado em ambos os sistemas, sendo observada uma pequena quantidade de óleo livre.

Figura 1- Microscopia ótica das microcápsulas de gelana contendo $6 \%$ de óleo de pequi, $70 \%$ de água, $24 \%$ de Tween 80 e 1\% de gelana. A) Aumento de 40x e B) aumento de 10x. Barra da escala $=10 \mu \mathrm{m}(\mathrm{A})$ e $50 \mu \mathrm{m}(\mathrm{B})$.
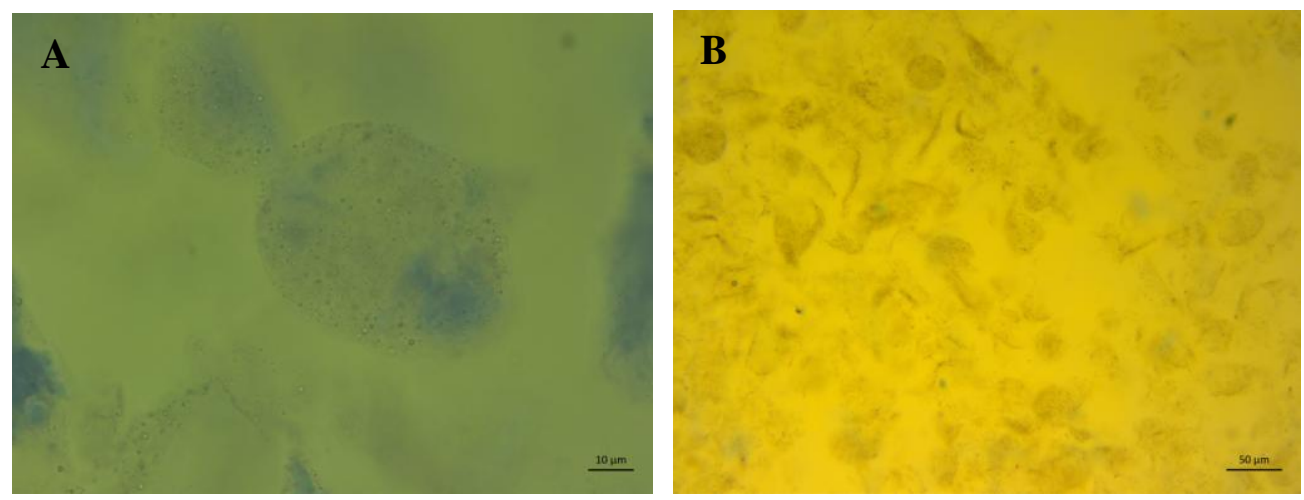

Figura 2- Microscopia ótica das microcápsulas de $\kappa$-carragena contendo $6 \%$ de óleo de pequi, $70 \%$ de água, 24\% de Tween 80 e 1\% de $\kappa$-carragena. A) Aumento de 40x e B) aumento de 10x. Barra da escala $=10 \mu \mathrm{m}(\mathrm{A})$ e $50 \mu \mathrm{m}(\mathrm{B})$.
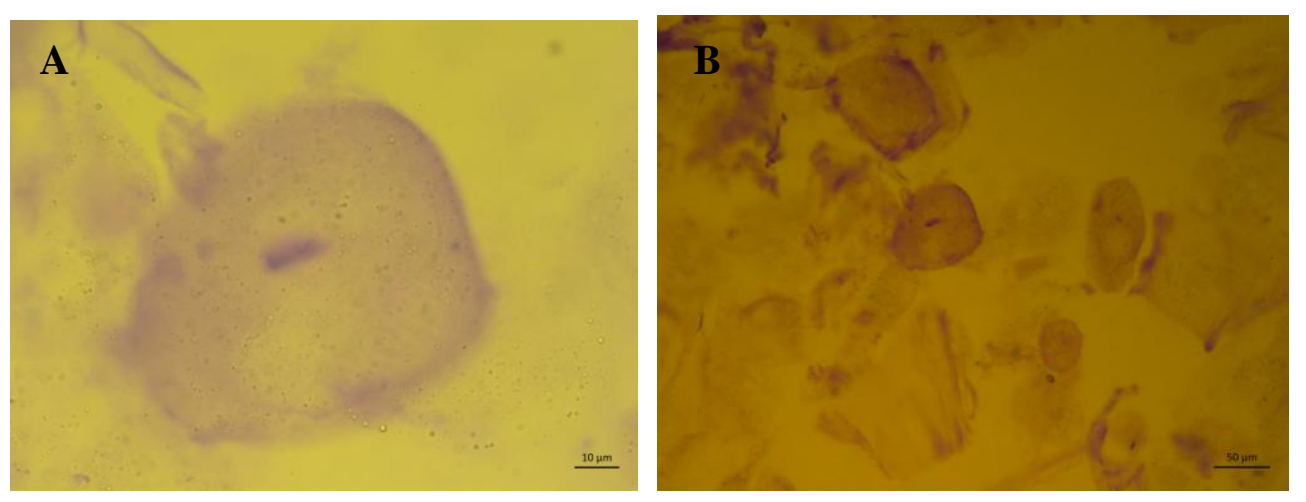

A partir da análise em espectrofotômetro pode-se quantificar o ácido retinóico presente nas microcápsulas de gelana, $\kappa$-carragena, microemulsão utilizada para o preparo das microcápsulas e na mistura do óleo de pequi contendo ácido retinóico empregada no preparo das microemulsões. As análises foram realizadas logo após o preparo dos sistemas, e após quatro dias, com o intuito de avaliar a estabilidade do ácido retinóico livre e encapsulado, como mostrado na Tabela 1.

A partir dos dados da Tabela 1 pode-se observar que as concentrações de ácido retinóico no óleo livre e na microemulsão O/A foram próximas e até superiores aos valores teóricos adicionados. No entanto, concentrações muito baixas de ácido retinóico estavam presentes nas microcápsulas, indicando baixa eficiência de encapsulação (em torno de $1 \%$ e 
4\% para as microcápsulas de gelana e $\kappa$-carragena, respectivamente). Com isso, pode-se concluir que existiram grandes perdas do composto nas soluções de $\mathrm{KCl}$ e $\mathrm{CaCl}_{2}$ durante a reticulação das microcápsulas e outras etapas do processo de formação das microcápsulas, como a extrusão das microemulsões. Lira (2007) avaliou a encapsulação em sistemas de alginato e quitosana preparados por gelificação iônica e também verificou uma eficiência de encapsulação muito baixa, inferior a 5\%. Sistemas que apresentaram elevada eficiência de encapsulação (superior a 57\%) foram aqueles que utilizaram uma matriz hidrofóbica como sistema de encapsulação, como é o caso das nanopartículas lipídicas sólidas (Das et al., 2011; Silva et al., 2015).

Tabela 1- Dados da concentração do ácido retinóico no óleo livre, microemulsão e nas microcápsulas contendo gelana e $\kappa$-carragena como materiais de parede

\begin{tabular}{ccc}
\hline & Dia 0 & Dia 4 \\
\hline Microcápsula de gelana & Concentração (\%) & Concentração (\%) \\
Microcápsula de א-carragena & 0,0009 & $0^{*}$ \\
Microemulsão O/A & 0,0035 & $0^{*}$ \\
Óleo contendo ácido retinóico livre & 0,0861 & 0,0239 \\
& 2,4213 & 1,1201
\end{tabular}

* a quantidade foi inferior à sensibilidade do método utilizado para a quantificação do ácido retinóico.

Analisando-se os dados obtidos no dia 4 (Tabela 1) pode-se notar uma diminuição nas concentrações, tanto do ácido retinóico encapsulado quanto do ácido retinóico presente no óleo e na microemulsão, indicando que houve degradação do ácido retinóico em todas as situações avaliadas. Para o ácido retinóico encapsulado houve $100 \%$ de degradação, enquanto que o composto livre presente no óleo apresentou 53\% de degradação e na microemulsão apresentou $72 \%$ de degradação. Estes resultados indicam que tanto as microcápsulas com gelana quanto as com $\kappa$-carragena não foram eficazes para a proteção do ácido retinóico encapsulado, além de promoverem uma maior degradação quando comparados com o ácido retinóico presente no óleo e nas microemulsões. Provavelmente a microemulsão e, principalmente, as microcáspulas promoveram uma maior superfície de contato do ácido retinóico com o oxigênio, o que levou a uma degradação acelerada do ácido retinóico encapsulado.

\section{CONCLUSÃO}

A partir dos resultados obtidos neste trabalho pode-se concluir que foi possível o preparo das microcápsulas a partir de microemulsões gelificadas com o uso de gelana e $\kappa$ carragena, e que a gelana apresentou melhor resultado como material de parede, apresentando microcapsulas mais esféricas e uniformes. No entanto, não foi possível encapsular grande quantidade de ácido retinóico nos microgéis tanto com o uso de gelana quanto com $\kappa-$ carragena, indicando que a metodologia utilizada não foi eficiente para a encapsulação. Assim, seria necessário utilizar outras técnicas para encapsular este composto de interesse e protegê-lo de maneira eficiente em relação à degradação frente a fatores externos, como exposição ao oxigênio. 


\section{REFERÊNCIAS}

BUREY, P.; BHANDARI, B. R; HOWES, T.; GIDLEY, M. J. Hydrocolloid Gel Particles: Formation, Characterization, and Application. Critical Reviews in Food Science and Nutrition, v. 48, p. 361-377, 2008.

CUI, J.; YU, B.; ZHAO, Y.; ZHU, W.; LI, H.; LOU, H.; ZHAI, G. Enhancement of oral absorption of curcumin by self-microemulsifying drug delivery systems. International Journal of Pharmaceutics, v. 371, p. 148-155, 2009.

DAS, S.; NG, W. K.; KANAUJIA, P.; KIM, S.; TAN, R. B. H. Formulation design, preparation and physicochemical characterizations of solid lipid nanoparticles containing a hydrophobic drug: Effects of process variables. Colloids and Surfaces B: Biointerfaces, v. 88, p. 483-489, 2011.

HWANG, S. R.; LIM, S.-J.; PARK, J.-S.; KIM, C.-K. Phospholipid-based microemulsion formulation of all-trans-retinoic acid for parental administration. International Journal of Pharmaceutics, v. 276, p. 175-183, 2004.

JENNING, V.; GOHLA, S. H. Encapsulation of retinoids in solid lipid nanoparticles (SLN). Journal of Microencapsulation, v. 18, p.149-158, 2001.

LARA, V. C. D. Desenvolvimento de nanocápsulas contendo ácido retinóico para tratamento tópico da acne. Dissertação (Mestrado em Ciências Farmacêuticas) - Faculdade de Farmácia, Universidade Federal de Minas Gerais, 2008.

LIRA, A. A. M. Desenvolvimento, caracterização e avaliação de sistemas microestruturados para veiculação de ácido retinóico na pele. Tese (Doutorado em Ciências Farmacêuticas) - Faculdade de Ciências Farmacêuticas de Ribeirão Preto, Universidade de São Paulo, 2007.

LIN, C.-H.; FANG, Y.-P.; AL-SUWAYEH, S. A.; YANG, S.-Y.; FANG, J.-Y. Percutaneous Absorption and Antibacterial Activities of Lipid Nanocarriers Loaded with Dual Drugs for Acne Treatment. Biological and Pharmaceutical Bulletin, v. 36, p. 276-286, 2013.

MCCLEMENTS, D. J. Encapsulation, protection, and release of hydrophilic active components: Potential and limitations of colloidal delivery systems. Advances in Colloid and Interface Science, v. 219, p. 27-53, 2015.

SILVA, E. L.; CARNEIRO, G; DE ARAÚJO, L. A.; DE JESUS, M.; TRINDADE, V.; YOSHIDA, M. I.; ORÉFICE, R. L.; DE MACÊDO, L.; DE CARVALHO, M. A. R.; SANTOS, S. G.; ASSIS, G.; GOULART, C.; ALVES, R. J; FERREIRA, L. A. M. Solid Lipid Nanoparticles Loaded with Retinoic Acid and Lauric Acid as an Alternative for Topical Treatment of Acne Vulgaris. Journal of Nanoscience and Nanotechnology, v. 15, p. 792-799, 2015.

TANCRÈDE-BOHIN, E.; BALDEWECK, T.; DECENCIÈRE, E.; BRIZION, S.; VICTORIN, S.; PARENT, N.; FAUGERE, J.; SOUVERAIN, L.; BAGOT, M.; PENA, A.-M. Non-invasive short-term assessment of retinoids effects on human skin in vivo using multiphoton microscopy. Journal of the European Academy of Dermatology and Venereology, v. 29, p. 673-681, 2015.

TRAPASSO, E.; COSCO, D.; CELIA, C.; FRESTA, M.; PAOLINO, D. Retinoids: New use by innovative drug-delivery systems. Expert Opinion on Drug Delivery, v. 6, p. 465-483, 2009.

TROTTA, M.; UGAZIO, E.; PEIRA, E.; PULITANO, C. Influence of ion pairing on topical delivery of retinoic acid from microemulsions. Journal of Controlled Release, v. 86, p. 315-321, 2003. 